\title{
Pain Medicine: This is a Time for Neurologists to Take Over the Initiative
}

\author{
Arunas Sciupokas* \\ Department of Neurology, Head of the Postgraduate course “Pain Medicine”, Lithuanian University of Health Sciences, Kaunas, Lithuania \\ *Corresponding author: Assoc.Prof. Arunas Sciupokas, Dept. of Neurology, LSMU Mickeviciaus 9, Kaunas LT-44307, Lithuania, \\ Email: arunas.sciupokas@lsmuni.lt
}

\begin{tabular}{|c|c|}
\hline ARTICLE INFO & ABSTRACT \\
\hline Received: 幽 February 08, 2019 & Abbreviations: CRPS: Complex Regional Pain Syndrome; CNS: Central Nervous System; \\
\hline Published: 幽 February 19, 2019 & $\begin{array}{l}\text { LANSS: Leeds Assessment of Neuropathic Symptoms and Signs; NPQ: Neuropathic Pain } \\
\text { Ouestionnaire: ABPMR: American Board of Physical Medicine and Rehabilitation; ABA: }\end{array}$ \\
\hline $\begin{array}{l}\text { Citation: Arunas Sciupokas. Pain } \\
\text { Medicine: This is a Time for Neurol- } \\
\text { ogists to Take Over the Initiative. Bi- }\end{array}$ & $\begin{array}{l}\text { American Board of Anesthesiology; ABPN: American Board of Psychiatry and Neurolo- } \\
\text { gy; ABMS: American Board of Medical Specialties; IASP: International Association for the } \\
\text { Study of Pain }\end{array}$ \\
\hline
\end{tabular}

omed J Sci \& Tech Res 14(5)-2019.

BJSTR. MS.ID.002600.

\section{Opinion}

Although pain management as core of healing ("Sedare dolorum divinum est") has been declared by Hippocrates in old ages, the Pain medicine as a field of contemporary medicine exists slightly more than half century. The sunrise of pain medicine is closely related to the name of John Bonica who laid the background for pain medicine in the middle of XX century [1]. John Bonica was the first anesthesiologist who understood a new responsibility of specialty in a changing pain theatre. He found that the painful sensation in many cases can be long staying as undesirable attendant which breaks normal lives to many people. Jonh Bonica has declared new duties mandatory for anesthesiologists - to be leader physicians who mobilize healthcare specialists to work together and help people with chronic unbearable pain. He believed in a team approach to the field of pain management, meaning that is necessary to incorporate various specialties to treat acute and chronic pain. He developed the concept of multidisciplinary pain clinics, and multimodal approach in pain management soon has become the basis of new field of medicine. In 1973 John Bonica tweeted a pain forum of outstanding clinicians and researchers to the meeting near Seattle (USA) and founded the International Association for the Study of Pain (IASP), the organization which unites healthcare professionals of more than one hundred thirty specialties and is the world leader for pain treatment and research. Nowadays all conceptual and strategical issues dealing with pain belongs to IASP, including Chronic pain declaration as a disease (2001), Montreal declaration that access to pain management is a fundamental human right (2010), and chronic pain syndromes classification to be published in the new ICD-11 soon [2].

Over the past decade's new health technologies especially imaging techniques, made a significant input to understanding of pain chronicity processes. Imaging has taken the stage in its ability to evaluate functional, morphological and chemical changes coming from pain both provide a new window of understanding disease neurobiology related to chronic pain. Measurements of grey matter and resting state networks have reported loss of grey matter in the thalamus and dorsolateral prefrontal cortex for patients with chronic back pain [3]. Similar changes have been reported in various neurological conditions including trigeminal neuropathy and migraine [4]. The clinical evaluation of resting state networks may provide a signature for specific pain syndromes and allows least objectively differentiate pain from non-painful conditions. The evidences say that the migraine brain is abnormal even outside of attacks and that repeated attacks are leading to functional and structural alterations in the brain, which may in turn drive the transformation of migraine to its chronic form [5]. 
In fact neuroimaging studies have generated a new understanding of how pain affects the brain. The notion that changes in sensory systems only are the predominant process in chronic pain has been replaced by a conceptualization of chronic pain as a very complex CNS state in which patterns of sensory system activation are integrated with activity in other brain systems, including emotional, cognitive and modulatory processes. Chronic pain condition affects many brain regions such as the anterior cingulate cortex, insular cortex, ventrolateral orbitofrontal area, amygdala, striatum, thalamus, hypothalamus, rostral ventromedial medulla, periaqueductal grey, pons (locus coeruleus), red nucleus, medulla oblongata. Chronic pain should be considered a brain disease in which alterations in neural networks affect multiple aspects of brain function, structure and chemistry. Chronic pain evokes changes in areas of the brain involved in sensory, emotional and modulatory systems and are a direct consequence of pain or secondary to comorbid changes such as depression or anxiety.

Evidences from brain research studies do suggest a notion that pain disease particularly and pain medicine at all are parts of neuroscience and neurology. Chronic pain is a frequent component of many neurological disorders, affecting $20-40 \%$ of patients for many primary neurological diseases. Whether pain originates in the central or peripheral nervous system, it frequently becomes centralized through false responses within the central nervous system that can profoundly alter brain systems and jointly change behavior. In many cases chronic pain is a direct result of the neurological disease otherwise may even be considered an integral part of the underlying disease. Pain produces changes throughout the CNS with effects on emotional processing, and this interaction is complex as pain causes depression and depression causes pain.

The list of painful conditions, which are on responsibility of neurologist is long:
a) nerve injury pain;
b) neuropathic pain;
c) central pain;
d) spinal stenosis;
e) low back pain;
f) lumbar and cervical radiculopathy;
g) post herpetic neuralgia;
h) complex regional pain syndromes;

i) headache and facial pain syndromes, including trigeminal neuralgia, and many others. The prevalence of pain among neurological disorders also is remarkable. Pain is present for $63 \%$ multiple sclerosis patients (mostly neuropathic pain), and relevant depression is common for $50 \%$ of them [6]. The etiology of pain in MS may involve a more complex phenomenon including local cytokine processes or alterations in white and grey matter integrity of networks. Pain is common for 40-60 percent of Parkinson's disease patients with co-morbid depression up to $45 \%$ of them. Dopaminergic systems are involved in the modulation and integration of sensory information and the response to pain, and pain symptoms increase and decrease with dopaminergic fluctuation [7]. Post-stroke pain (thalamic syndrome) is relevant to 8-14 percent of all stroke patients, and depression leads to $36 \%$ of them [8]. Painful diabetic neuropathy is 63 percent of all diabetic neuropathies. There are neurological conditions where pain is the leading syndrome and is prevalent for almost all patients (syringomyelia, traumatic brain disease, spinal cord injury, postherpetic neuralgia). Complex regional pain syndrome (CRPS) also is $100 \%$ prevalent pain disease, where depression leads in $41 \%$ cases. Brain imaging studies of CRPS suggest that all patients with neuropathic pain have alterations in brain systems that may result in cognitive and other behavioral changes, which may go unrecognized because they are not as prominent as the pain symptoms. Migraine is the primary headache and chronic pain disease itself and is prevalent up to $17.1 \%$ among females [9] and fibromyalgia is prevalent up to $4 \%$ of all population [10].

Practical experiences show that near half of patients who coming to neurology clinics suffer pain. The task for neurologist while meeting a patient in the clinic is to distinguish type of the pain (nociceptive vs. neuropathic), to clarify is it peripheral neuropathic of central pain syndrome, to establish pain syndrome as the disease and initiate treatment. Central pain syndrome is a neurological condition caused by damage to or dysfunction of the central nervous system (CNS), which includes the brain, brainstem, and spinal cord. This syndrome can be caused by stroke, multiple sclerosis, tumors, epilepsy, brain or spinal cord trauma, or Parkinson's disease. Central pain syndrome often begins shortly after the causative injury or damage, but may be delayed by months or even years, especially if it is related to post-stroke pain. A detailed somatosensory examination at bedside is the first step to establish a right diagnosis. Peripheral and central neuropathic pains have the different mechanisms (deafferentation vs. disinhibition), onset time after injury (immediate vs. delayed), location pattern (dermatomal vs. pathway), even allodynia signs might be different (dynamic vs. static). Nobody else as neurologist experienced in pain diagnostics can get answers to those delicate somatosensory signs. A subtle examination of pain patients is necessary also because pain diagnosis and research have the lack of an objective measurement of pain. Neurologists should use clinical questionnaires and screening tools such as pain DETECT, psychophysical measures, and imaging, Leeds Assessment of Neuropathic Symptoms and Signs (LANSS); Neuropathic Pain Questionnaire (NPQ)]. Also tools adopted from the psychiatric literature, which can be used to evaluate other dimensions of chronic pain, including quality of life, depression, anxiety, catastrophizing and drug-abuse potential. There is an urgent need to develop biomarkers for pain [4]. Imaging has taken this opportunity in its ability to evaluate pain in neurology and 
functional, morphological and chemical changes in disease states and provide a new window of understanding disease neurobiology related to chronic pain. Having markers for chronic pain would allow for a specific diagnosis of pain and for measures of treatment clinical efficacy (given that the current success rates of analgesics for chronic pain are $30 \%$ ).

Pain is common in neurological diseases affecting various parts of the PNS and the CNS. Most neurologists treat patients with chronic pain, but only few neurologists specialize in the pain medicine. Since John Bonica's time worldwide leaders in pain medicine practice continue to be anesthesiologists, and this is confirmed by the IASP membership (2442 anesthesiologists vs 289 neurologists) [11]. One of the main reasons why only few neurologists specialize in pain management may be related to lack of formal training in pain management. According to survey of practicing neurologists in US thirty percent of respondents reported they were adequately trained to diagnose pain-related disorders. However, the large majority $(89 \%)$ stated the need for more pain related training during residency and 91\% wanted more pain education for practicing neurologists [12]. The survey of neurology program directors showed that only $29 \%$ of neurology programs had a pain specialist on faculty and $5 \%$ had a mandatory pain clinic rotation. Over the past decades a situation in US improved. The American Academy of Neurology published a pain medicine core curriculum for neurology residents. The American board of physical medicine and rehabilitation (ABPMR) offers subspecialty certification in pain medicine and cosponsors this certification along with the American Board of Anesthesiology (ABA) and the American Board of Psychiatry and Neurology (ABPN). Pain medicine is recognized by the American Board of Medical Specialties (ABMS) as a neurologic subspecialty [13].

However, a situation for neurologists in Europe is not so optimistic. The European Pain Federation (EFIC), the biggest organization representing IASP in Europe, is doing great for pain medicine developments in the region. Those include education programs as pain schools and pain fellowships for physicians. Recently established the program and examination for European pain medicine diploma is an important acceleration on the European pain road, too [14]. This led to unification and common criteria development for accreditation in pain medicine. Nevertheless, a certification of pain medicine as subspecialty in separate specialties including neurology, seems will take longer process or even be approved by countries themselves decisions. Such process recently has started in Lithuania. By the decree of Minister of Health pain medicine de facto is recognized as subspecialty for anesthesiology, neurology, and neurosurgery [15]. The residency programs of those specialties are going to be updated with pain medicine courses. Meanwhile the postgraduate pain fellowship program for physicians already is approved by medical faculty of the university. Curriculum of this program include basics of pain medicine and specific articles of pain neurology where biopsychosocial approach is essential. During studies students will learn about neurological pain syndromes and achieve competences in physical, emotional, and cognitive evaluation of patients' pain. Training in interventional procedures, behavioral and psychological approaches, pharmacotherapy, and rehabilitation also is will be covered.

Probably right now is time for neurologists to turn on higher gear and take responsibility for patients' pain and suffering. Education in pain medicine should take place during neurology residency, and pain refresher courses should be included in neurology postgraduate programs. A great work remains to encourage neurologists become specialists in pain medicine.

\section{References}

1. https://en.wikipedia.org/wiki/John_Bonica - accessed 06/02/2019

2. Treede RD, Rief W, Barke A, Aziz Q, Benoliel R, et al. (2015) A classification of chronic pain for ICD-11. PAIN 156(6): 1003-1007.

3. Apkarian AV, Sosa Y, Sonty S, Levy RM, Parrish TB, et al. (2004) Chronic back pain is associated with decreased prefrontal and thalamic gray matter density. J Neurosci 24(46): 10410-10415.

4. Borsook D, Hargreaves R (2010) Brain Imaging in Migraine Research. Headache 50(9): 1523-1527.

5. Borsook D (2012) Neurological diseases and pain. Brain 135(2): 320344 .

6. Foley PL, Vesterinen HM, Laird BJ, Sena ES, Colvin LA, et al. (2013) Prevalence and natural history of pain in adults with multiple sclerosis: systematic review and meta-analysis. Pain 154(5): 632-642.

7. Simuni T, Sethi K (2008) Nonmotor manifestations of Parkinson's disease. Annals of Neurology 64(2): S65-S80.

8. Kumar, Kalita J, Kumar G, Misra UK (2009) Central Poststroke Pain: A Review of Pathophysiology and Treatment. Anesthesia and analgesia 108(5): 1645-1657.

9. Lipton RB, Bigal ME, Diamond M, Freitag F, Reed ML, et al. (2007) Migraine prevalence, disease burden, and the need for preventive therapy. Neurology 68(5): 343-349.

10. Staud R (2009) Chronic widespread pain syndrome and fibromyalgia: Two sides of the same coin? Curr Rheumatol Rep 11(6): 433-436.

11. www.iasp-pain.org - accessed 06/02/2019

12. Galer B, Keran C, Frisinger M (1999) Pain medicine education among American neurologists: A need for improvement. Neurology 52(8): 1710-1712.

13. Lalani I (2006) Emerging subspecialties in neurology: Pain medicine. Neurology 67(8): 1522-1523.

14. https://europeanpainfederation.eu/education/pain-exams/europeandiploma-in-pain-medicine-edpm/.

15.h t t p s : / / e - s e i m a s.lrs . l t / p o r tal/le gal Act/lt/ TAD/86209b21f15811e89d4ad92e8434e309 
ISSN: 2574-1241

DOI: 10.26717.BJSTR.2019.14.002600

Arunas Sciupokas. Biomed J Sci \& Tech Res

(c) (i) This work is licensed under Creative

Submission Link: https://biomedres.us/submit-manuscript.php

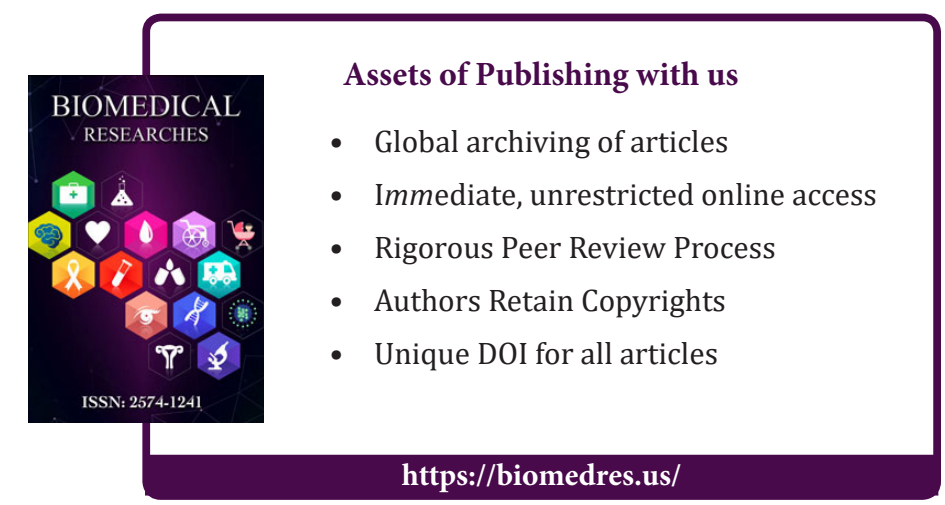

